\title{
SURFACE- AND FIELD-INDUCED AFLC STRUCTURES DETECTED BY DIELECTRIC SPECTROSCOPY
}

\author{
JAN LAGERWALL, PER RUDQUIST, SVEN LAGERWALL, \\ BENGT STEBLER \\ Chalmers University of Technology, Department of Microelectronics and \\ Nanoscience, Liquid Crystal Physics; SE-412 96 Göteborg, Sweden
}

\section{(Received in final form November 7,2001$)$}

In order to better understand which features in dielectric spectra of antiferroelectric liquid crystals (AFLCs) are due to the bulk director geometry, and which are due to surface-induced structures, we have performed dielectric spectroscopy measurements with simultaneous texture monitoring on two SmC*-exhibiting AFLC homologues (11- and 12F1M7), at varying cell gap. Such AFLCs are strongly affected by surface action even in fairly thick cells $(d \approx 15 \mu \mathrm{m})$, with heavy supercooling of the $\mathrm{SmC}^{*}$ phase as the most obvious result. We show that the supercooled structure can be removed by $\mathrm{AC}$-field treatment in the $\mathrm{SmC}_{\mathrm{a}}{ }^{*}$ phase, but some domains may stay in a polar geometry, as reflected in both texture and dielectric signature. On heating from the antiferroelectric $\mathrm{SmC}_{\beta}{ }^{*}$ subphase into $\mathrm{SmC}^{*}$, meta-stable non-helical domains may form at cell gaps much larger than the helical pitch. These domains give rise to a lowfrequency dielectric absorption not seen in bulk SmC* samples.

Keywords antiferroelectric liquid crystals; dielectric spectroscopy; texture studies; surface-induced supercooling; surface-stabilization

\section{INTRODUCTION}

Dielectric spectroscopy often plays a crucial role in phase characterization of antiferroelectric liquid crystals (AFLCs). However, the spectra must be interpreted keeping confinement effects in mind in order not to 


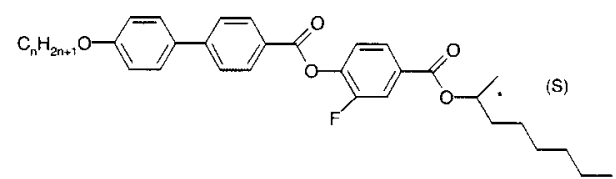

FIGURE 1. Chemical structure of the investigated homologous (S)- $n \mathrm{~F} 1 \mathrm{M} 7, n=11,12$.

attribute surface-induced phenomena to bulk phases [1-4]. In this work we show how dielectric measurements may provide valuable information not only on the phase studied, but also on the particular director geometry which is present in the sample.

We have investigated the single-compounds $(S)$-11- and 12F1M7 (Figure 1), exhibiting the phase sequences listed in Table 1, using wedgeshaped cells equipped with multiple electrodes, thus permitting measurements at cell gaps between $d=1 \mu \mathrm{m}$ and $d=40 \mu \mathrm{m}$. The two homologues are qualitatively very similar, differing only in transition temperatures and phase temperature ranges. As the ranges of the subphases are considerably broader in $11 \mathrm{~F} 1 \mathrm{M} 7$, we will here give examples only from this compound. Comparisons with other studies of the $n=12$ homologue [5 7], can still be made on a qualitative level.

TABLE 1. Phase sequences, as obtained by dielectric spectroscopy measurements in thick $(d \approx 40 \mu \mathrm{m})$ cells, and characteristic polarization and tilt values of the investigated compounds $n \mathrm{~F} 1 \mathrm{M} 7$.

\begin{tabular}{|c|l|l|l|}
\hline$n$ & $\begin{array}{l}\text { Phase sequence on heating } \\
\left(\text { transition temperatures in }{ }^{\circ} \mathrm{C}\right)\end{array}$ & $\begin{array}{l}\text { Saturated } P_{s}{ }^{(b)} \\
\left(\mathrm{nCm}^{-2}\right)\end{array}$ & $\begin{array}{l}\text { Saturated tilt } \\
(b) \\
\text { (degrees) }\end{array}$ \\
\hline 11 & $\begin{array}{l}\mathrm{SmC}_{\mathrm{a}}{ }^{*}-70-\mathrm{SmC}_{\gamma}{ }^{*}-76-\mathrm{SmC}_{\beta}{ }^{*}- \\
80.5-\mathrm{SmC}^{*}-89-\mathrm{SmA}^{*}\end{array}$ & 105 & 27 \\
\hline 12 & $\begin{array}{l}\mathrm{SmC}_{\mathrm{a}}{ }^{*}-79.5-\mathrm{SmC}_{\gamma}{ }^{*}-83-\mathrm{SmC}_{\beta}{ }^{*} \\
-85-\mathrm{SmC}^{*}-92-\mathrm{SmA}^{*}\end{array}$ & 100 & 27 \\
\hline
\end{tabular}

a: The subphase notation used in this paper is based on the recent recognition [8] that the phase just above $S_{m} C_{\gamma}{ }^{*}$ in optically pure $M H P O B C$, originally denoted $S m C_{\beta}{ }^{*}$ by the Fukuda group, is the four-layer periodicity antiferroelectric subphase also referred to as " $A F$ ", $S m C_{\gamma 2}{ }^{*}$ or $S m C_{F 12}$. Through the reattribution of the shorthand $\mathrm{SmC}_{\beta}{ }^{*}$ to this subphase, one solves the disturbing nomenclature problem which has been an inherent obstacle of AFLC research until now. This matter is pursued in reference [9].

$b$ : The saturated polarization and tilt-angle values are approximations taken $65^{\circ} \mathrm{C}$ below the transition between $\mathrm{Sm}^{*}$ and $\mathrm{SmC}$. From Parghi et al. [10]

In Figure 2, the dielectric absorption spectra for $11 \mathrm{~F} 1 \mathrm{M} 7$ in a $36 \mu \mathrm{m}$ sample are presented. At such large cell gap, the different phases are eas- 

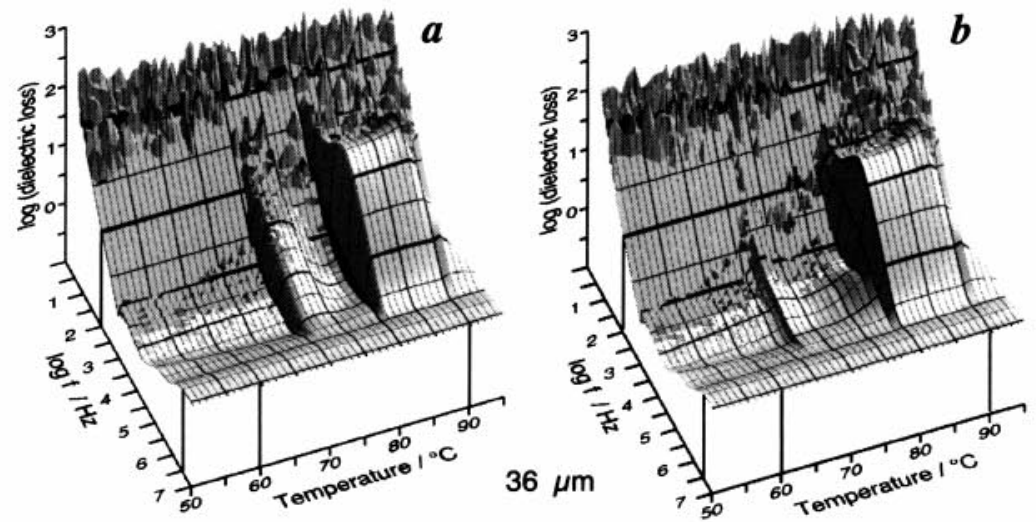

FIGURE 2. Dielectric absorption spectra of $11 \mathrm{~F} 1 \mathrm{M} 7$ at $36 \mu \mathrm{m}$ cell gap on heating (a) and on cooling (b).

ily recognized in the heating spectrum, while on cooling, the $\mathrm{SmC}_{\gamma}$ * phase almost does not develop due to the large supercooling of $\mathrm{SmC}_{\beta}{ }^{*}$. We have earlier shown [11] that cell gap reduction drastically alters the phase behavior of 11- and 12F1M7, with subphase suppression and supercooling of $\mathrm{SmC}^{*}$ as most obvious consequences. Below $d \approx 5 \mu \mathrm{m}$, the $\mathrm{SmC}^{*}$ response on cooling stays active until the onset of crystallization. Such supercooling seems to be a common behavior of AFLCs exhibiting the $\mathrm{SmC}^{*}$ phase, which means that proper thin-cell studies of the other mesophases of such compounds are possible only if the supercooled structure has been adequately removed. As a method for such removal, we have investigated the effect of addressing the sample in the $\mathrm{SmC}_{\mathrm{a}}{ }^{*}$ phase with an AC electric field at an amplitude above the AF-F threshold.

In our first report on the $n \mathrm{~F} 1 \mathrm{M} 7$ homologues [11], we also studied 10F1M7 which does not exhibit the $\mathrm{SmC}^{*}$ phase but instead $\mathrm{SmC}_{\alpha}{ }^{*}$. We then concluded that this compound is much less sensitive to surface influence than the other two homologues. Apparently, the presence of the synclinic, synpolar SmC* phase in the phase sequence has an immense impact on the behavior of AFLCs in thin cells, and the SmC* phase behavior is therefore of prime interest in the present work. It should be pointed out that the $\mathrm{SmC}^{*}$ phase in this case has a very short pitch $(p \sim 0.3 \mu \mathrm{m})$. Therefore, we do not expect any visible trace of the helical structure in planar (bookshelf) samples in the absence of external fields. If a weak electric field is applied, a tilting of the effective optic axis away from the layer normal is to be expected. We encounter this linear electrooptic effect, called the Deformed Helix Mode [12], in this study. 

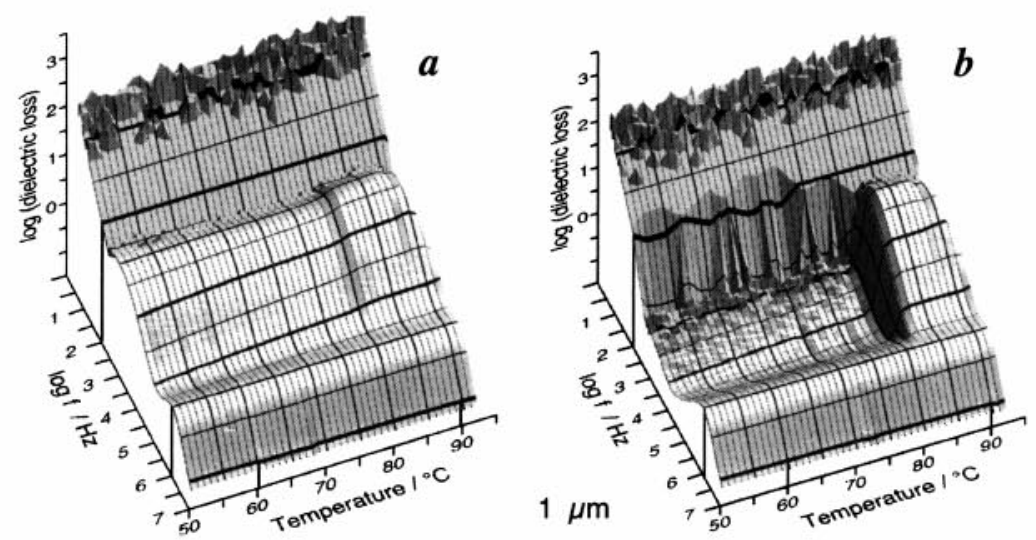

FIGURE 3. Dielectric absorption spectra on heating of $11 \mathrm{~F} 1 \mathrm{M} 7$ for $1 \mu \mathrm{m}$ cell gap; without prior electric field treatment (a) and after ACaddressing at $50^{\circ} \mathrm{C}$, corresponding to (bulk) $\mathrm{SmC}_{\mathrm{a}}{ }^{*}$ (b).

\section{EXPERIMENTAL}

The special cells used for this study are described in detail in reference [11]. Planar alignment was assured by polyimide-coated substrates, one of which was unidirectionally rubbed. Throughout the mesophase range, the optical textures and dielectric response were monitored using a Sony SSC-DC58AP video camera connected to a National Instruments PCI1411 framegrabber card, and an HP4192A dielectric bridge, respectively. The cells were kept in a custom-built liquid-heated hot stage, the temperature of which was regulated by a Julabo F25-HD circulator. The cell could be moved within the hot stage such that the camera always registered the texture at the particular electrode area which was connected to the bridge. For AC electric field treatment, a Hung Chang G305 function generator and an FLC Electronics 10x-amplifier were used.

\section{RESULTS AND DISCUSSION}

\section{Removing of Supercooled SmC* Structures}

In very thin cells the $\mathrm{AC}$-addressing method turned out to be quite efficient. Figure 3 shows the dielectric absorption spectra for $d=1 \mu \mathrm{m}$ on heating, with and without $\mathrm{AC}$-addressing prior to the measurement. While the left, unaddressed, spectrum reveals a SmC*-like response 
throughout the whole mesophase temperature range (i.e. also where the bulk phase is $\mathrm{SmC}_{\mathrm{a}}{ }^{*}, \mathrm{SmC}_{\gamma}{ }^{*}$ or $\mathrm{SmC}_{\beta}{ }^{*}$ ), the addressed spectrum clearly shows that most of the supercooled polar structure was indeed removed by addressing the sample. However, the phase sequence still differed from the bulk case, as no sign of the subphases could be seen. The phase taking their place was now $\mathrm{SmC}_{\mathrm{a}}{ }^{*}$, so we can conclude that when the subphases are suppressed by surface action, the phase replacing them can be either $\mathrm{SmC}^{*}$ or $\mathrm{SmC}_{\mathrm{a}}{ }^{*}$, which one depending on the state of the sample before entering the subphase temperature region.

The removal of polar structures was, however, not complete. In the addressed $1 \mu \mathrm{m}$ spectrum, a weak response centered around $f \approx 1 \mathrm{kHz}-$ approximately the same frequency as that of the $\mathrm{SmC}^{*}$ phase absorption at this cell gap - not typical of the $\mathrm{SmC}_{\mathrm{a}}{ }^{*}$ phase, was observed. This component of the spectrum was present in all addressed samples up to $d=24 \mu \mathrm{m}$, growing stronger with increasing cell gap up to $12 \mu \mathrm{m}$, then rapidly decreasing in importance. The $\mathrm{SmC}_{\mathrm{a}}{ }^{*}$ texture (the $T=50^{\circ} \mathrm{C}$, $d=12 \mu \mathrm{m}$ case is shown in Figure $4 a$ ) was non-uniform and revealed the presence of small domains where the optic axis was not pointing along the layer normal. Apparently, the liquid crystal in these domains had not relaxed to the anticlinic state after switching, but instead exhibited some kind of polar, probably twisted structure. A director twist along the substrate normal is always connected to a polarization splay, the fluctuations in which would explain the dielectric absorption connected to the presence of these domains [1]. With decreasing cell gap, the twist energy increases, rendering the twisted state less stable [13]. This explains the more uniform $\mathrm{SmC}_{\mathrm{a}}{ }^{*}$ state at $d=1 \mu \mathrm{m}$. Both subphases were present at $d=12 \mu \mathrm{m}$ and it is interesting to note that the antiferroelectric $\mathrm{SmC}_{\beta}{ }^{*}$ phase developed a structure which was more uniformly non-polar than that of $\mathrm{SmC}_{\mathrm{a}}{ }^{*}$. This can be deduced from the quite absorption-free spectrum between $76^{\circ} \mathrm{C}$ and $80^{\circ} \mathrm{C}$, in combination with the corresponding textures which show that the domains with optic axis tilting away from the layer normal had almost completely disappeared (Figure $4 b$ ).

\section{Spontaneous SmC* Helix Suppression at Large Cell Gaps}

As the temperature was raised further, a most interesting observation was made at the onset of the $\mathrm{SmC}^{*}$ phase. The dielectric spectrum here exhibited a prominent low-frequency (LF) absorption $(f \leq 100 \mathrm{~Hz})$, easily visible between $81^{\circ} \mathrm{C}$ and $83^{\circ} \mathrm{C}$ in the spectrum of Figure 4 , in addition to the expected SmC* helix distortion mode. Such an absorption has previously been taken as a sign of a new phase [5], but texture photos at temperatures where it is active clearly show that this is not a correct interpretation. The 


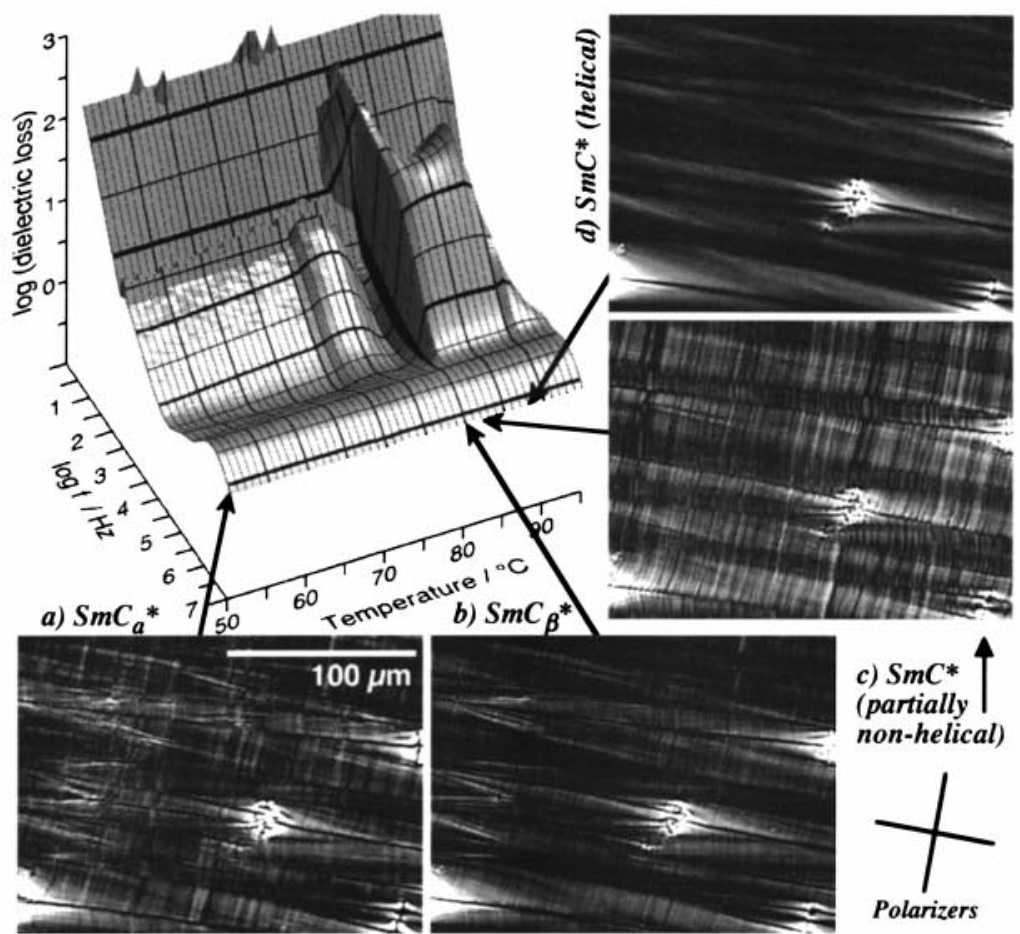

FIGURE 4. Dielectric absorption spectrum on heating from addressed $\mathrm{SmC}_{\mathrm{a}}{ }^{*}$ at $12 \mu \mathrm{m}$ cell gap, and sample textures at selected points of the measurement: $a$ ) $\left.\mathrm{SmC}_{\mathrm{a}} *\left(50^{\circ} \mathrm{C}\right), b\right) \mathrm{SmC}_{\beta} *\left(80^{\circ} \mathrm{C}\right), c$ ) SmC* with non-helical stripes $\left.\left(82^{\circ} \mathrm{C}\right), d\right)$ helical SmC* $\left(88^{\circ} \mathrm{C}\right)$.

(See Color Plate VIII)

texture in Figure $4 c$ reveals a spatial coexistence of helical (optic axis along the layer normal) and non-helical (optic axis tilted away from the layer normal), apparently meta-stable, $\mathrm{SmC}^{*}$ domains. We will return to the issue of why one may expect to see surface-stabilization of this kind at such thick cells (the helical pitch of the $\mathrm{SmC} *$ phase is approximately $0.3 \mu \mathrm{m}$, i.e. some 40 times smaller than the cell gap) towards the end of this paper. On continued heating, the non-helical domains turned dark and the LF absorption quickly decreased in magnitude. At $86^{\circ} \mathrm{C}$ both the texture and the spectrum were those of a normal short-pitch SmC* phase (Figure $4 d$, where no trace of the helix can be seen due to its short pitch).

The situation was even clearer at $3 \mu \mathrm{m}$ cell gap (Figure 5). Also here it was difficult to get a well-aligned $\mathrm{SmC}_{\mathrm{a}}{ }^{*}$ state after the $\mathrm{AC}$-field treatment. The texture revealed a large amount of bright defects and the accompanying LF absorption was active, even though it was not as strong 


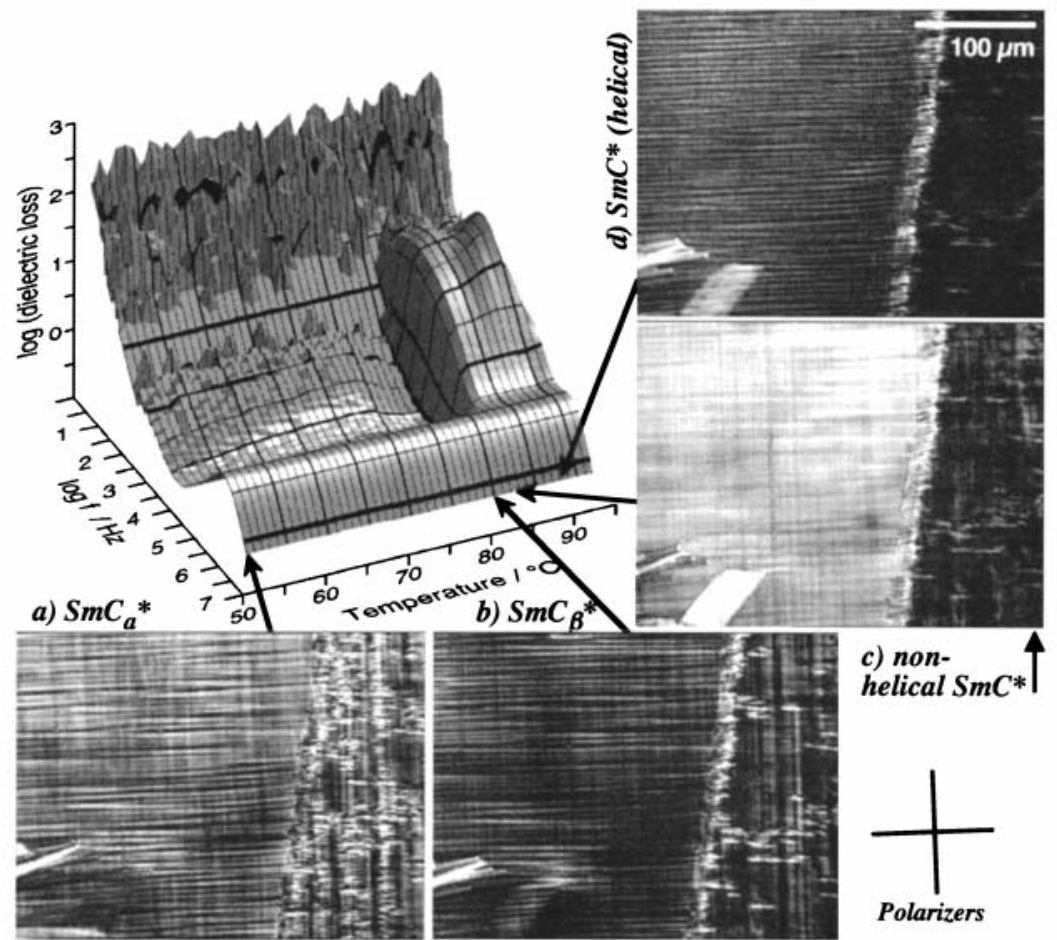

FIGURE 5. Dielectric spectrum on heating from addressed $\mathrm{SmC}_{\mathrm{a}}{ }^{*}$ at $3 \mu \mathrm{m}$ cell gap, and sample textures at selected points of the measurement: a) $\left.\left.\mathrm{SmC}_{\mathrm{a}}{ }^{*}\left(50^{\circ} \mathrm{C}\right), b\right) \mathrm{SmC}_{\beta} *\left(80^{\circ} \mathrm{C}\right), c\right)$ non-helical SmC* $\left.\left(83^{\circ} \mathrm{C}\right), d\right)$ helical SmC* $\left(88^{\circ} \mathrm{C}\right)$. (See Color Plate IX)

as in the $12 \mu \mathrm{m}$ sample. This time there was no trace of any $\mathrm{SmC}_{\gamma}{ }^{*}$ phase on heating, but at the temperature of the bulk inter-subphase transition, the non-antiferroelectric domains disappeared, leaving a rather absorptionless $\mathrm{SmC}_{\beta}{ }^{*}$ part of the spectrum and a much darker texture. At the transition to $\mathrm{SmC}^{*}$, the whole electrode area texture turned bright (Figure $5 \mathrm{c})$. In other words, nowhere in the addressed sample could the SmC* helix form immediately after the phase transition, but instead the phase fully adopted the non-helical meta-stable structure. The birefringence color of the $\mathrm{SmA}^{*}$ phase at this electrode is orange-pink, so the bright yellowish texture in Figure $5 c$ tells us that the effective birefringence was lower than in $\mathrm{SmA}^{*}$. As a uniformly unwound $\mathrm{SmC}^{*}$ state exhibits a birefringence larger than in $\mathrm{SmA}^{*}$, we can conclude that the spontaneously formed non-helical $\mathrm{SmC}^{*}$ state must have a non-uniform structure. The decreased effective birefringence would be adequately explained $e . g$. by 
a twist along the substrate normal. When the bright texture was observed, the dielectric spectrum exhibited an LF absorption similar to that described previously for $d=12 \mu \mathrm{m}$, even though the absorption frequency was higher at the small cell gap. This increase in frequency with decrease in cell gap supports the idea that the meta-stable structure has a director twist and a polarization splay [1]. The non-helical state remained for a few degrees on heating, but at $2-3 \mathrm{~K}$ below the $\mathrm{SmC}^{*}-\mathrm{A}^{*}$ transition, the LF absorption disappeared and the spectrum changed to a more standard SmC* spectrum, dominated by the helix distortion mode. At the same time, the texture went back to a uniform dark one (Figure $5 d$ ).

The connection between lines along the layers and a low-frequency absorption has been described by Bourny and co-workers for the case of $\mathrm{C} 8$ and C10 tolane [3]. They developed a model according to which the lines are explained by the pairwise merging of (invisible) $\pi$-disclinations at the surface, to form (visible) $2 \pi$-disclinations in bulk. This will lead to a polarization splay within the layers, occurring at the height of the $2 \pi$ disclinations which separate the helical bulk from the unwound surface region. The movement up and down of the disclinations would then lead to a polarization fluctuation explaining the absorption, which they therefore refer to as the "surface layer mode". At first sight, this model may seem to explain also our observations, but there are a few problems. First of all, the presence of $2 \pi$ disclinations would not explain the tilting of the optic axis away from the layer normal. Second, the spacing of these lines should, if our interpretation of the model is correct, be equal to the pitch of the phase. But the SmC* pitch in these materials has been measured to be approximately $0.3 \mu \mathrm{m}$, while the distance between the defect lines in our textures were on the order of $2-3 \mu \mathrm{m}$.

The bright, non-helical SmC* structure, appeared spontaneously only on heating. On cooling, we could see two types of behavior, depending on cell gap. At $d<5 \mu \mathrm{m}$ the SmC* phase was (partially) supercooled down to the onset of crystallization, and the texture then simply retained the character of the helical SmC* phase, with the optic axis along the layer normal. The dielectric spectrum at these cell gaps only exhibited one absorption, which we attribute to the normal $\mathrm{SmC}^{*}$ helix distortion mode. At cell gaps between $5 \mu \mathrm{m}$ and $12 \mu \mathrm{m}$, an LF absorption appeared in the supercooled $\mathrm{SmC}^{*}$ temperature range, even though it was much weaker than the mode seen on heating. As there were no clear signs of surfacestabilization, it is uncertain if the absorptions observed on cooling and heating were of the same type. A possibility is that the cooling absorption was the surface layer mode described by Bourny et al., as suggested by the presence of a large amount of defect lines when the mode was active. 


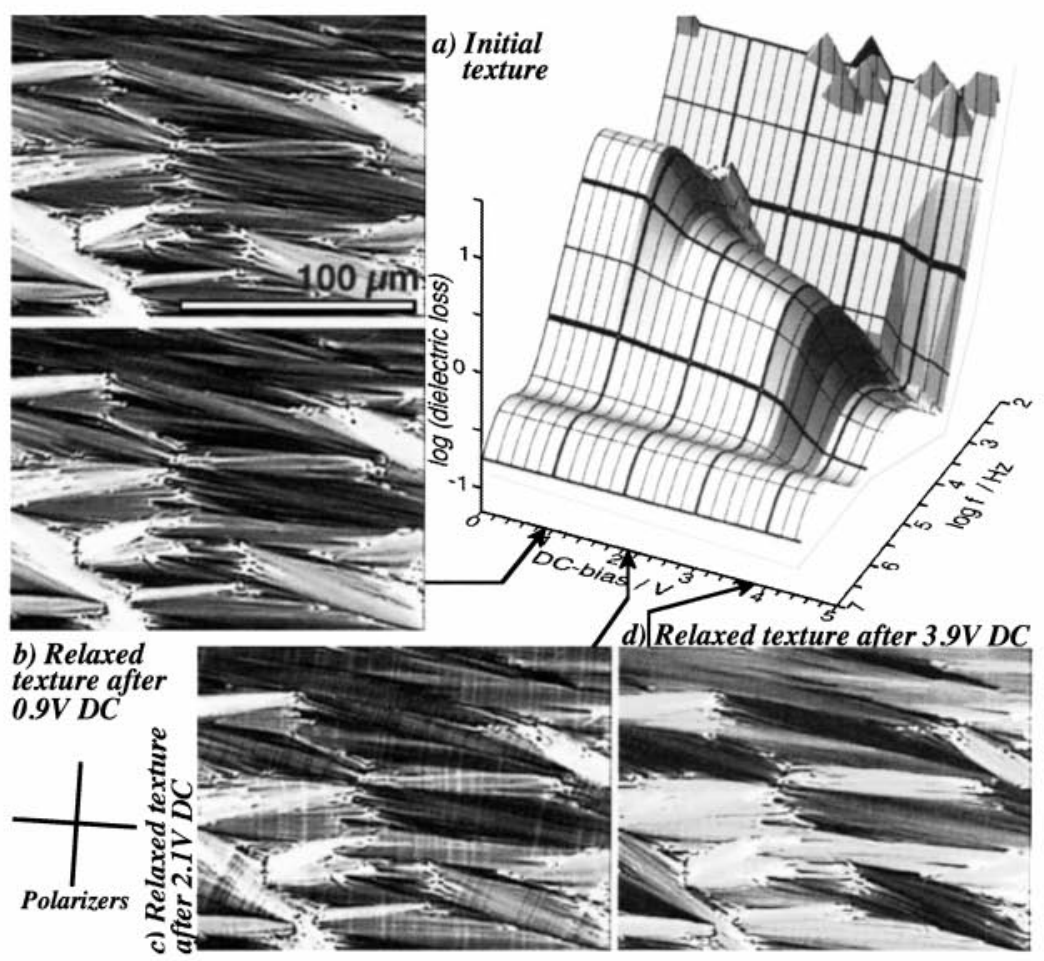

FIGURE 6. Dielectric absorption spectrum of $11 \mathrm{~F} 1 \mathrm{M} 7(d=8.5 \mu \mathrm{m}$, $\left.T=84^{\circ} \mathrm{C} \leftrightarrow \mathrm{SmC} *\right)$ as a function of DC-voltage, and selected post-bias textures, showing the three regimes of the $\mathrm{SmC}^{*}$ helix. unwinding.

(See Color Plate X)

However, the defect lines started appearing several degrees above the temperature at which the dielectric absorption could be seen, and they were actually also present in the thinner cells, where no LF absorption was seen, so it seems that the defect lines on their own cannot explain the presence of the additional absorption.

In order to understand what gives rise to the meta-stable non-helical SmC* state, it is illuminating to study the case of electric field-induced helix unwinding (Figure 6). We have recorded the dielectric response under application of a DC-bias voltage at $84^{\circ} \mathrm{C}\left(\mathrm{SmC}^{*}\right)$ at $8.5 \mu \mathrm{m}$ sample thickness. The bias voltage $V_{D C}$ was increased in steps of $0.3 \mathrm{~V}$ from $0 \mathrm{~V}$ to $+5 \mathrm{~V}$ and after each measurement a negative compensatory voltage $V_{D C}$ was applied for as long as the measurement had taken. At each step the texture was photographed before and during application of the $+V_{D C}$ voltage, as well as at zero field directly after removing the measuring 
bias, before application of the compensatory DC-voltage. The textures in Figure 6 all show the sample after the measurement and after releasing the positive DC-voltage. As is obvious from the spectrum and the textures, the unwinding process may be divided into three stages:

- 0V-0.9V DC. This is the elastic regime, in which the Deformed Helix Mode electro-optic effect is active. With the DC-voltage applied, a tilting away from the layer normal of the optic axis is observed. The electric field produces small uniform unwound regions, separated by soliton twist walls with an approximate spacing of the helical pitch $p$.

- 0.9V - 3.8V DC. Beginning of the plastic regime. Complete unwinding begins in the sense that soliton walls start to be removed, leaving uniform regions extending a distance along the layer normal substantially larger than $p$. During the process, the region of twist is pushed closer to the substrate with polarization opposite to the field direction, and probably the final stage is the switching of the liquid crystal closest to this surface, as suggested by the texture images.

- DC-voltage $>\sim 3.8 \mathrm{~V}$. The sample is uniformly unwound, i.e. neither helix nor soliton twist-walls exist any more.

The zero-field post-bias texture from each stage clearly shows that the removal of soliton walls is a crucial step. Within the first stage, the sample always relaxed back fully to the initial texture. In contrast, on passing the threshold to the second stage, the relaxed texture was markedly different from the initial one: the sets of layers which had been fully switched to a non-helical state stayed in that state and thus showed up as brighter stripes in the field-free texture. The corresponding dielectric spectrum shows not only a decrease in the helix distortion mode susceptibility, reflecting the fact that some layers could no longer contribute to the mode, but at the threshold voltage a low-frequency component is visible. This is very similar to the dielectric signature of the Frederiks transition at which an SSAFLC sample starts to transform (the tilt-plane moves out from being perpendicular to the field to finally align along the field) before the directors will be switched to a synclinic geometry [14]. This similarity is not surprising, since the removal of a soliton twist wall is - as in the case of the Frederiks transition - a fluctuation-induced step: the electric field has no torque on the director inside the wall, where the polarization points exactly opposite to the electric field, and the tightly twisted regions surrounding it prefer untwisting in opposite senses. Thus fluctuations will decide in which sense the wall will finally be untwisted.

Going to the last stage, finally, where the field was strong enough to fully unwind the helix, the relaxed texture was completely different from 
the initial one: the optic axis is now everywhere tilted away from the layer normal, producing a bright green texture, even after removal of the field.

It is clear that the SmC* helix in these compounds has large difficulties to form once it has been unwound. The unwinding may be induced by an electric field, as in the above example, or it may be due to the influence of surfaces. At the cell gaps investigated in this study, one can hardly expect conventional surface-stabilization of the SmC* phase (SSFLC), as it exhibits a pitch in the order of $0.3 \mu \mathrm{m}$. But the $\mathrm{SmC}_{\beta}{ }^{*}$ phase, preceding $\mathrm{SmC}^{*}$ on heating, has a much longer pitch and this may be expected to be spontaneously surface-stabilized even at relatively large cell gaps. We therefore propose that the explanation to the non-helical SmC* domains observed on heating is that the sample enters the $\mathrm{SmC}^{*}$ phase coming from a surface-stabilized $\mathrm{SmC}_{\beta}{ }^{*}$ state. The phase transition can certainly occur independently of the formation of the helix, so the sample may be in the same helix-free state after that transition as after application of a DC-field strong enough to unwind the helix. As the rewinding of the helix is apparently connected to a high energy cost, this occurs only very slowly, leading to meta-stable non-helical states at cell gaps far too large to produce conventional SSFLC states.

\section{CONCLUSIONS}

With AFLCs exhibiting the SmC* phase, surface-induced effects are important at cell gaps up to $d \approx 15 \mu \mathrm{m}$. The most important effect is a large supercooling of $\mathrm{SmC}^{*}$, but this supercooled structure can be (partially) removed by application of an $\mathrm{AC}$ electric field in the $\mathrm{SmC}_{2}$ * phase. While the $\mathrm{SmC}_{\gamma}{ }^{*}$ phase is expelled at $d<10 \mu \mathrm{m}$, the $\mathrm{SmC}_{\beta}{ }^{*}$ phase may exist down to $3 \mu \mathrm{m}$ cell gap, but it can be surface-stabilized (non-helical) at $d<25 \mu \mathrm{m}$. The formation of the short-pitch $\mathrm{SmC}^{*}$ helix from an unwound state (via switching or by heating from surface-stabilized $\mathrm{SmC}_{\beta}{ }^{*}$ ) costs much energy, and therefore partial surface-stabilization is possible at cell gaps much larger than the helical pitch of the $\mathrm{SmC}^{*}$ phase. An anomalous $\mathrm{SmC}^{*}$ response, which has previously been mistakenly interpreted as a sign of a new phase type, is connected to such non-helical structures.

\section{Acknowledgements}

Dr. D. Parghi and the group of Professor J. W. Goodby (Hull, UK) are gratefully acknowledged for supplying the samples of 11- and 12F1M7. 
Financial support from the Chalmers Graduate School of Materials Science (Göteborg, Sweden) and The Royal Swedish Physiographic Society (Lund, Sweden) is gratefully acknowledged. The authors wish to thank Dr. D. Krüerke, Dr. F. Gießelmann and Dr. F. Gouda for stimulating discussions.

\section{References}

[1] V. Novotna, M. Glogarova, A. Bubnov, H. Sverenyak, Liq. Cryst., 23 (1997), pp. 511-518

[2] M. Cepic, G. Heppke, J. M. Hollidt, D. Lötzsch, B. Zeks, Ferroelectrics, 147 (1993), pp. 159-170

[3] V. Bourny, J. Pavel, P. Gisse, H.T. Nguyen, Ferroelectrics, 241 (2000)

[4] J. P. F. Lagerwall, D. D. Parghi, G. Heppke, Ferroelectrics, 244 (2000), pp. $511-521$

[5] Yu. P. Panarin, O. Kalinovskaya, J. K. Vij, and J. W. Goodby, Phys. Rev. E, 55 (1997), pp. 4345-4353. Note that there is an important printing error in this report: the cell gap at which the low-frequency absorption is seen in the $\mathrm{SmC}^{*}$ phase is $8 \mu \mathrm{m}$, not $50 \mu \mathrm{m}$ as stated in the paper (personal communication with Yu. Panarin, (2001)).

[6] L. J. Baylis, H. F. Gleeson, A. J. Seed, P. J. Styring, M. Hird and J. W. Goodby, Mol. Cryst. Liq. Cryst., 328 (1999), pp. 13-20

[7] N. M. Shtykov, J. K. Vij, R. A. Lewis, M. Hird and J. Goodby, Phys. Rev. E, 62 (2000), pp. 2279-87

[8] M. Cepic, E. Gorecka, D. Pociecha, B. Zeks and R. Dabrowski, Manuscript in preparation (2001)

[9] J. P. F. Lagerwall, P. Rudquist, S. Lagerwall, Poster presentation P281 at FLC 2001, Washington DC (USA), manuscript in preparation (2001)

[10] D. D. Parghi, S. M. Kelly and J. W. Goodby, Mol. Cryst. Liq. Cryst., 332, (1999), pp. 313-320

[11] J. P. F. Lagerwall, D. D. Parghi, D. Krüerke, F. Gouda and P. Jägemalm, accepted for publication in Liq. Cryst. (2001)

[12] B. I. Ostrovskij, A. Z. Rabinovich, V. G. Chigrinov, in L. Bata (ed.), Advances in Liquid Crystal Research and Applications, Pergamon Press, Oxford - Akadémiai Kiadó, Budapest (1980), pp.469-482

[13] S. T. Lagerwall, Ferroelectric and Antiferroelectric Liquid Crystals, Wiley-VCH (1999)

[14] P. Rudquist, J. P. F. Lagerwall, K. D'havé, J. G. Meier, S. T. Lagerwall, Oral presentation 1-10 at FLC 2001, Washington DC (USA), manuscript in preparation (2001) 